\title{
Preparation and Characterization of Lyotropic Liquid Crystalline Aromatic Copolyamides Containing Twisty and Non-coplanar Moiety
}

\author{
Pengtao LiU, ${ }^{1}$ Qizhen Liang, ${ }^{1}$ Cheng Liu,${ }^{1,2}$ Xigao Jian, ${ }^{1,2, \dagger}$ Dingyi Hong, ${ }^{3}$ and Yang $\mathrm{LI}^{1}$ \\ ${ }^{1}$ Department of Polymer Science \& Materials, Dalian University of Technology, Dalian, 116012, P. R. China \\ ${ }^{2}$ Liaoning Research Center of High-performance Resin Engineering and Technology, Dalian, 116012, P. R. China \\ ${ }^{3}$ Science \& Technology Development Division, SINOPEC, Beijing, 100029, P. R. China
}

(Received October 27, 2005; Accepted January 17, 2006; Published May 15, 2006)

\begin{abstract}
A series of aromatic rigid-chain copolyamides were prepared from 1,2-dihydro-2-(4-aminophenyl)4-[4-(4-(aminophenoxyl)phenyl)](2H)phthalazin-1-one (DHPZ-DA), p-phenylenediamine (PPD), 1,4-bis(4-aminophenoxy)benzene (BAPOB) and terephthaloyl dichloride (TPC) by low temperature solution polycondensation. The polymers were produced with high yields and relatively high inherent viscosities, ranging from 1.74 to $4.31 \mathrm{dL} / \mathrm{g}$. The introducing of phthalazinone moiety and ether linkages into the main chain improved the solubility in some polar solvents. The $T_{\mathrm{g}}$ values of the polymers were in the range of $291-351^{\circ} \mathrm{C}$ and the 5 and $10 \%$ weight loss temperatures in nitrogen were in the range of $486-518$ and $509-538^{\circ} \mathrm{C}$, respectively, indicating their good thermal stability. WAXD measures indicated that these copolyamides were semicrystalline in nature. Most of the polymers exhibited nematic lyotropic liquid crystalline characteristics in concentrated $\mathrm{H}_{2} \mathrm{SO}_{4}$, NMP (1 wt \% LiCl) and DMAc (1 wt \% LiCl) solutions, as evidenced by polarizing light microscopy. [doi:10.1295/polymj.38.477]

KEY WORDS Lyotropic Liquid Crystalline / Copolyamides / Phthalazinone / Nematic /
\end{abstract}

Since the discovery of liquid crystalline, anisotropic ordering behaviors of liquid crystals (LCs) have been of considerable interest to academe and industry. ${ }^{1-4}$ Liquid crystalline polymers (LCPs) can be found in a number of commercial applications ranging from high strength engineering plastics to optical display devices. Polymers that exhibit liquid crystallinity, either in the melt or in their solutions, usually consist of comparatively rigid structures that confer high extension on the molecular chains. ${ }^{3-6}$ The structure of rigid chain polymers always contains aromatic rings together with functional groups, hydrogen bonding, and molecular symmetry. These structural factors, promoting strong intermolecular interaction and hence liquid crystallinity, unavoidably led to high melting temperatures and poor solubility of the resulting polymers which prevent their process or use in many applications. For example, poly ( $p$-phenylene terephthalamide) (PPTA) which is the chemical structure of $\operatorname{Kevlar}^{\circledR}$ is a lyotropic LCP and exhibits outstanding mechanical properties, good thermal stability, and excellent chemical resistance, but this polyamide fiber can only be spinned from its conc. $\mathrm{H}_{2} \mathrm{SO}_{4}$ solution. ${ }^{7}$

In an attempt to improve the solubility of rigid chain liquid crystalline polymers especially PPTA, many efforts have been made to modify the polymer chain structure. Some of these approaches include the incorporation of twist and non-planar moiety and flexible links into the polymer chain. ${ }^{8-10}$ It has been found that aromatic polyamides containing phthalazinone moiety and ether linkages in the polymer backbone exhibit excellent properties including being soluble in some polar aprotic solvents such as NMP, DMAc etc. ${ }^{11-14}$ But studying of the liquid crystalline behavior of these polyamides is only at the beginning.

It has been demonstrated that one of the prerequisites for a polymer to exhibit liquid crystallinity is the straightness and rigidity of the polymer chain, which can be related to persistence length. ${ }^{15-17}$ Flory predicted that for a rigid rod polymer chain to exhibit liquid crystallinity, the aspect ratio of the rodlike molecule should be larger than $6 .{ }^{17}$ It will be interesting to see rigid chain polymers containing a high percentage of twist non-planar moiety and ether linkages still exhibiting liquid crystallinity.

In the present article, 1,2-dihydro-2-(4-aminophenyl)-4-[4-(4-(aminophenoxyl)phenyl)] $(2 \mathrm{H})$ phthalazin1-one (DHPZ-DA) and 1,4-bis(4-aminophenoxy)benzene (BAPOB) were introduced into the main chain of PPTA by low temperature solution polymerization method. ${ }^{18}$ Thus a series of copolyamides containing varying ratios of twist non-planar moiety and ether linkages were obtained. The ability of the polymers to form LC solutions was tested. The structures of the copolyamides were characterized and their inherent viscosity, solubility, thermal properties, and crystallinity were also investigated.

${ }^{\dagger}$ To whom correspondence should be addressed (Tel: +86-0411-8365-3426, Fax: +86-0411-8363-9223, E-mail: xgjian@chem.dlut.edu.cn). 


\section{EXPERIMENTAL}

\section{Materials}

1,2-Dihydro-2-(4-aminophenyl)-4-[4-(4-(aminophenoxyl)phenyl)] (2H)phthalazin-1-one (DHPZ-DA, mp: 260-261 ${ }^{\circ} \mathrm{C}$ ) was prepared according to the reported method. ${ }^{11} p$-Phenylenediamine (PPD) was purified by vacuum sublimation. 1,4-Bis(4-aminophenoxy)benzene (BAPOB, mp: $174-175^{\circ} \mathrm{C}$ ) was prepared by the aromatic substitution reaction of hydroquinone and $p$-chloronitrobenzene and by the subsequent reduction of the intermediate bis( $p$-nitrophenoxy) compound. ${ }^{19}$ Terephthaloyl dichloride (TPC) was purified by vacuum distillation. Reagent grade $\mathrm{LiCl}$ was dried under vacuum at $180^{\circ} \mathrm{C}$ just before use. $\mathrm{N}$-methyl-2pyrrolidone (NMP) was purified by distillation under reduced pressure over $\mathrm{CaH}_{2}$ and stored over $4 \AA$ molecular sieves. Pyridine (Py) was refluxed over $\mathrm{KOH}$ pellets and distilled.

\section{Polymer Synthesis}

The copolyamide containing $10 \mathrm{~mol} \%$ DHPZ-DA, $30 \mathrm{~mol} \%$ BAPOB and $60 \mathrm{~mol} \%$ PPD is nominated as $\mathbf{P - 1 0 3 0 6 0}$ and the other denomination of the polymers are the same. A typical example of the synthesis of $\mathbf{P}$ 103060 is shown as follows. A mixture of $0.4205 \mathrm{~g}$ $(1.0 \mathrm{mmol})$ DHPZ-DA, $0.8770 \mathrm{~g}(3.0 \mathrm{mmol})$ BAPOB, $0.6489 \mathrm{~g}(6.0 \mathrm{mmol}) \mathbf{P P D}$ and $0.40 \mathrm{~g} \mathrm{LiCl}$ were charged into a three-neck flask containing $30 \mathrm{~mL} \mathrm{NMP} \mathrm{and}$ $1.0 \mathrm{~mL}$ Py at $0{ }^{\circ} \mathrm{C}$. After all the diamines and salt were dissolved, $2.0423 \mathrm{~g}(10.0 \mathrm{mmol})$ TPC were added into the mixture. Then the system were maintained with stirring under $\mathrm{N}_{2}$ atmosphere for about $6 \mathrm{~h}$ at $0{ }^{\circ} \mathrm{C}$. The resulting copolyamide was crushed and poured into $400 \mathrm{~mL}$ ethanol/water $(1: 1, \mathrm{v} / \mathrm{v})$. The pale yellow massive copolymer was washed thoroughly with hot water and dried then extracted with acetone for $8 \mathrm{~h}$ and dried under vacuum overnight at $100^{\circ} \mathrm{C}$. The yield was 99\%. Anal. calcd for P-103060: C, 72.50\%;
H, 4.1\%; N, 9.49\%. Found: C, 70.52\%; H, 4.23\%; N, $9.30 \%$.

\section{Measurements}

Inherent viscosities $\left(\eta_{\text {inh }}\right)$ were measured by Ubbelohde viscometer at a concentration of $0.5 \mathrm{~g} / \mathrm{dL}$. FT-IR spectra were recorded by reflection method with a Thermo Nicolet Nexus 470 Fourier transform infrared (FT-IR) spectrometer. ${ }^{1} \mathrm{H}$ NMR spectra were obtained using a Varian INOVA 400M nuclear magnetic resonance. Elemental analysis was performed on Carld Erba1106 CHN elemental analyzer. Differential scanning calorimetry (DSC) analysis and thermogravimetric analysis (TGA) were performed on Netzsch 204 DSC and Nstzsch 209 TG instruments, respectively. All samples were tested in flowing $\mathrm{N}_{2}$ at a heating rate of $20^{\circ} \mathrm{C} / \mathrm{min}$. The wide-angle $\mathrm{X}$-ray diffraction (WAXD) measurements were performed on a Rigaku D/max 2400 automatic X-ray diffractometer using Ni-filtered $\mathrm{Cu} \mathrm{K} \alpha$ radiation $(40 \mathrm{~V}$, $100 \mathrm{~mA}$ ) at room temperature. The rotated velocity of the goniometry was $4^{\circ} / \mathrm{min}$. Tensile properties of the thin polymer film specimens (about $8 \mathrm{~mm}$ wide and $60 \mathrm{~mm}$ long) were evaluated at room temperature on a Shimadzu AG-2000A tester and the extension rate was $100 \mathrm{~mm} / \mathrm{min}$. The textures of the copolyamides were identified with an Olympus BH-2 polarizing light microscope (PLM).

\section{RESULTS AND DISCUSSION}

\section{Polymer Synthesis}

Although Yamazaki-Higashi phosphorylation method starting from dicarboxylic acid and diamine is the widely used procedure in the laboratory, it is difficult to get high molecular weight polyamide. ${ }^{19-21}$ The low temperature solution polycondensation of diacidchloride with diamines is a convenient method for the preparation of high molecular weight polyamide. The synthesis route is shown in Scheme 1. By chang-

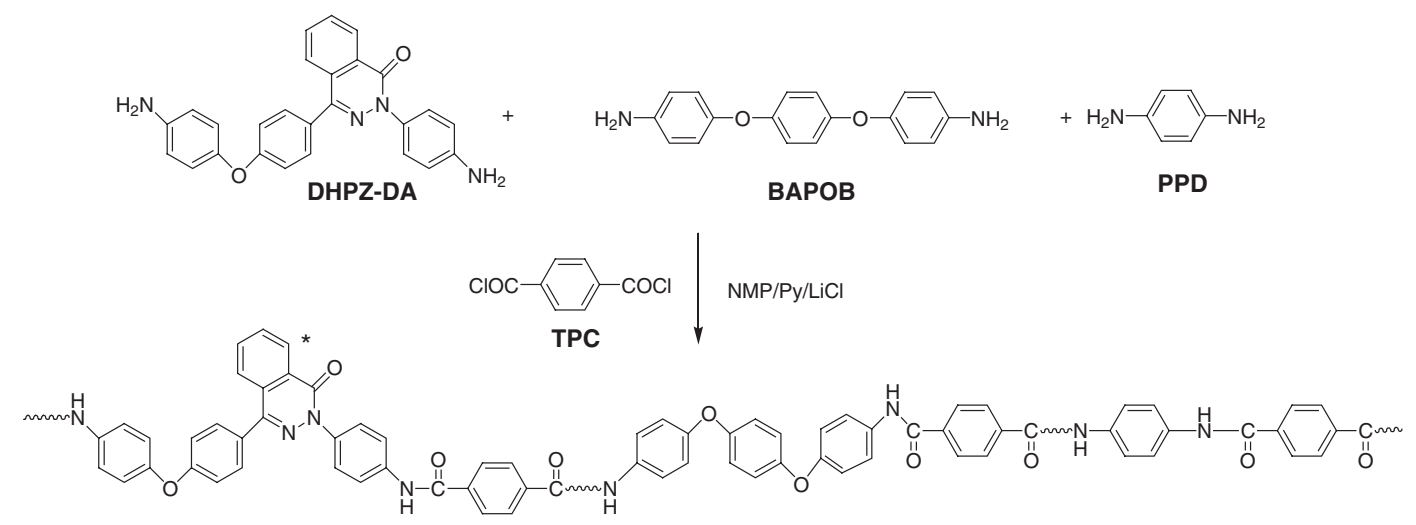

Scheme 1. The synthesis route of the copolyamides. 
ing the molar ratios of the diamines and optimizing the reaction parameters, we have successfully got a series of novel copolyamides with the inherent viscosity $\left(\eta_{\text {inh }}\right)$ values ranged from 1.74 to $4.31 \mathrm{dL} / \mathrm{g}$ measured in NMP $(1 \mathrm{wt} \% \mathrm{LiCl})$ or conc. sulfuric acid according to their solubilities. Obvious rod climbing phenomena and stir opalescence were observed during the starting period of polymerization. When the percentages of PPD were more than $60 \%$, such as P101080 and P-102070, the reaction systems changed into gel state quickly, the dry of the solutions appeared, and the polymers were splitted into small particles with the intensively stirring within $20 \mathrm{~min}$. When the percentages of PPD were in the range of $40-60 \%$, the polymer were in jelly state and did not drop when they were attached to the wall of the flask, so just static placing was needed in the later reaction process and the color of these products were pale yellow. While the percentages of PPD were less than 40\%, such as P-404020 and P-206020, the systems were very viscous liquid and stirring could go on until the reaction was stopped and the polymers were white (Table I).

The structures of these resulting copolyamides were characterized by FT-IR and ${ }^{1} \mathrm{H}$ NMR. The representative FT-IR spectra of the polymers are shown in Figure 1. It showed the characteristic absorption bands near $3300 \mathrm{~cm}^{-1}$ due to $\mathrm{N}-\mathrm{H}$ stretch, $1653 \mathrm{~cm}^{-1}$ due to $\mathrm{C}=\mathrm{O}$ stretch, $1600 \mathrm{~cm}^{-1}$ due to $\mathrm{C}=\mathrm{N}$ stretch, $1516 \mathrm{~cm}^{-1}$ due to combined $\mathrm{N}-\mathrm{H}$ bend and $\mathrm{C}-\mathrm{N}$ stretch, $1248 \mathrm{~cm}^{-1}$ due to $\mathrm{Ph}-\mathrm{O}-\mathrm{Ph}$ stretch and 1112 $\mathrm{cm}^{-1}$ due to N-N stretch. The representative ${ }^{1} \mathrm{H}$ NMR spectrum of P-404020 is shown as Figure 2. In the spectrum the resonance of $\mathrm{N}-\mathrm{H}$ proton appeared at
Table I. Physical properties and solubility of the copolyamides

\begin{tabular}{|c|c|c|c|c|c|c|c|}
\hline \multirow[b]{2}{*}{ Copolymer } & \multirow{2}{*}{$\begin{array}{c}\eta_{\text {inh }}{ }^{\mathrm{a}} \\
(\mathrm{dL} / \mathrm{g})\end{array}$} & \multirow[b]{2}{*}{ Color } & \multicolumn{5}{|c|}{ Solubility $^{c}$} \\
\hline & & & NMP & $\begin{array}{l}\mathrm{NMP} \\
/ \mathrm{LiCl}^{\mathrm{d}}\end{array}$ & DMAc & $\begin{array}{l}\mathrm{DMAc} \\
/ \mathrm{LiCl}^{\mathrm{d}}\end{array}$ & $\begin{array}{c}\text { Conc. } \\
\mathrm{H}_{2} \mathrm{SO}_{4}\end{array}$ \\
\hline P-101080 & $2.59^{\mathrm{b}}$ & Yellow & - & +- & - & +- & + \\
\hline P-102070 & 3.63 & Yellow & +- & +- & - & +- & + \\
\hline P-103060 & 4.31 & Yellow & +- & + & +- & + & + \\
\hline P-202060 & 2.75 & Yellow & +- & + & +- & + & + \\
\hline P-203050 & 2.82 & Yellow & +- & + & +- & + & + \\
\hline P-206020 & 2.95 & White & $+^{\mathrm{e}}$ & + & +- & + & + \\
\hline P-301060 & 3.94 & Yellow & +- & + & +- & + & + \\
\hline P-303040 & 2.38 & Yellow & +- & + & +- & + & + \\
\hline P-402040 & 2.17 & Yellow & +- & + & +- & + & + \\
\hline P-404020 & 1.74 & White & $+^{\mathrm{e}}$ & + & +- & + & + \\
\hline
\end{tabular}

adetermined at a concentration of $0.5 \mathrm{~g} / \mathrm{dL}$ in NMP $(1 \mathrm{wt} \%$ $\mathrm{LiCl})$ at $25^{\circ} \mathrm{C}$. ${ }^{\mathrm{b}}$ determined at a concentration of $0.5 \mathrm{~g} / \mathrm{dL}$ in concentrated sulfuric acid at $25^{\circ} \mathrm{C}$. ${ }^{\mathrm{c}}$ Tested with $0.02 \mathrm{~g}$ of the polymers in $1 \mathrm{ml}$ of solvent: + : soluble at room temperature; +- : partially soluble; - : insoluble. ${ }^{\mathrm{d}}$ Solvent containing $1 \mathrm{wt} \% \mathrm{LiCl} .{ }^{\mathrm{e}} \mathrm{Good}$ films were casted from their NMP solutions. The tensile strength, initial modulus, and break elongation for P-206020 film were 141.2 Mpa, 2.18 Gpa, and 6.2\%; for P-404020 film were $157.8 \mathrm{Mpa}, 2.42 \mathrm{Gpa}$, and $6.7 \%$, respsctively.

the chemical shift of $10.32-10.62 \mathrm{ppm}$ and the resonance of $\mathrm{C}-\mathrm{H}$ of aromatic rings appeared at 7.12$8.46 \mathrm{ppm}$. The peak at $8.46 \mathrm{ppm}$ corresponded to the $\mathrm{C}^{*}-\mathrm{H}$ protons which is a special shift of phthalazinone. The ratio of integral area of the peaks of $\mathrm{N}-\mathrm{H}: \mathrm{C}^{*}-\mathrm{H}: \mathrm{C}-\mathrm{H}$ (except $\left.\mathrm{C}^{*}-\mathrm{H}\right)$ was $5.08: 1: 38.79$ which in very near the theoretical ratio of 5:1:39. Therefore the structure of the obtained copolymer was coincident with our design.

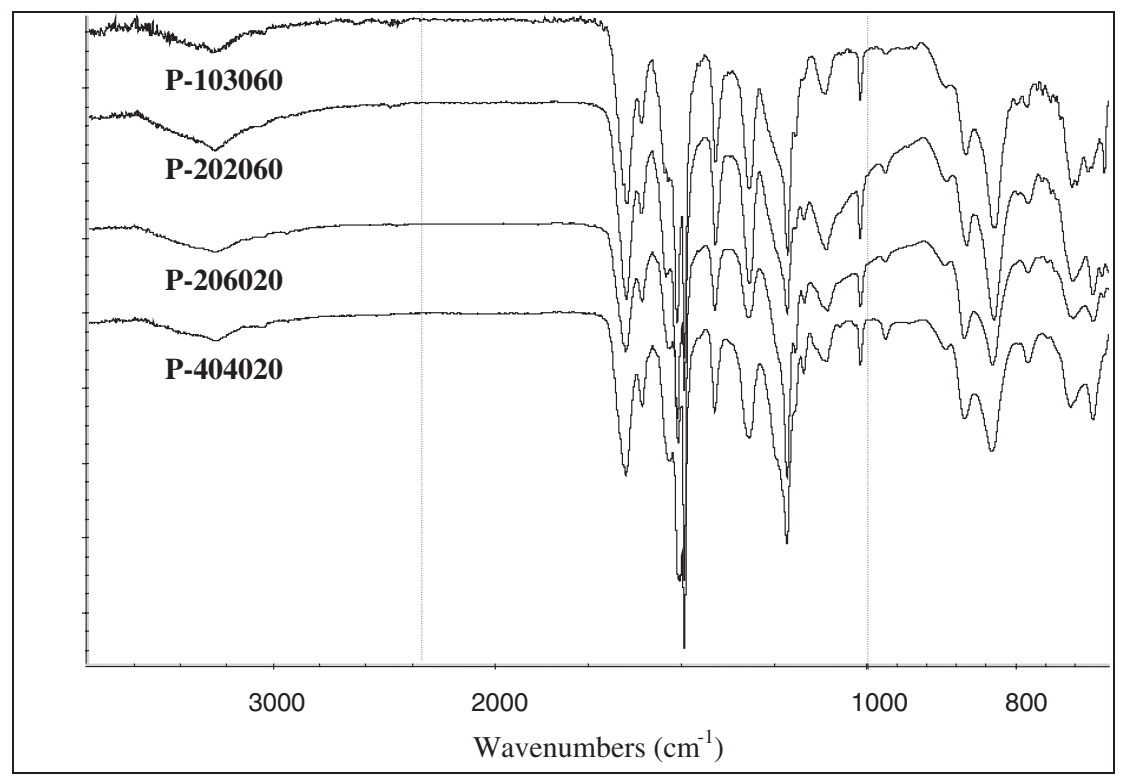

Figure 1. FT-IR spectra of copolyamides. 


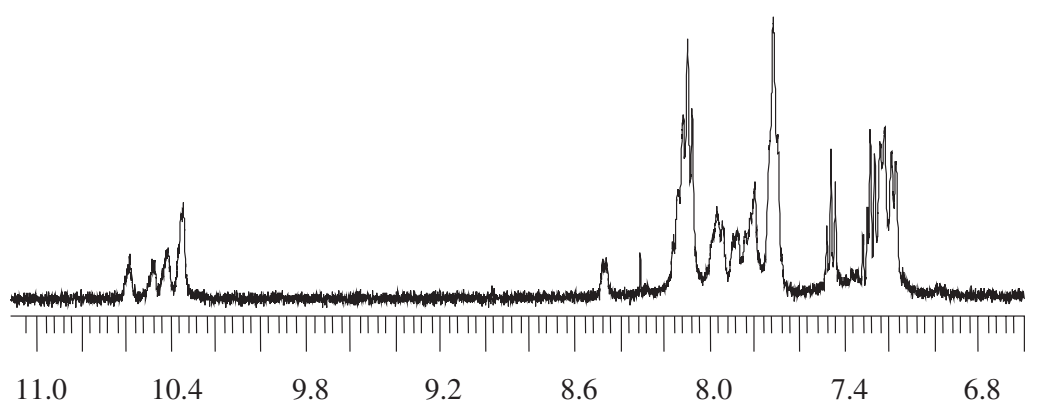

Figure 2. ${ }^{1} \mathrm{H}$ NMR spectrum of $\mathbf{P}-\mathbf{4 0 4 0 2 0}$.

\section{Polymer Solubility}

The solubility of the copolyamides was qualitatively tested in some typical organic solvents, and the results are reported in Table I. They showed improved solubility with the content of phthalazinone moieties and ether linkages increase, which was coincide with the phenomenon of polymerization. The more percentages of PPD in the action systems resulted in poor solubility and thus the time of homogeneous reaction was shortened. This is attribute to the fact that twist and non-coplanar phthalazinone moiety and ether linkages reduce the tight packing of the polymer chains and do not allow the macromolecules to pack closely through hydrogen bonds between amides groups, thus they facilitate the penetration of the small molecules of solvent into the polymer chains. Almost all the polymers were soluble in NMP or DMAc both containing few $\mathrm{LiCl}$. When the ratio of PPD is less than $40 \%$, the polymers were soluble in NMP. These make it possible for the polymers to form lyotropic LC in the polar solvents and to apply in spinning or casting processes.

\section{Thermal Properties}

To study the thermal behavior of the polymers, differential scanning calorimetry (DSC) test was performed between $50-400{ }^{\circ} \mathrm{C}$ in flowing $\mathrm{N}_{2}$ at a heating rate of $20^{\circ} \mathrm{C} / \mathrm{min}$. No transition due to softening or melting was observed. The glass transition temperatures $\left(T_{\mathrm{g}}\right.$, taken as the midpoint of the change in slope of the baseline) of polyamides were found in the range of $291-351{ }^{\circ} \mathrm{C}$ and the obtained results are collected in Table II. The thermal decomposition temperatures of the polymers were evaluated by means of thermogravimetric analysis (TGA) and derivative thermogravimetric (DTG) analysis at a heating rate of $20^{\circ} \mathrm{C} /$ min in flowing $\mathrm{N}_{2}$. All of these polymers showed similar decomposition behavior and the representative curves are shown in Figure 3. Most of the polymers showed no significant weight loss up to $400{ }^{\circ} \mathrm{C}$. But there were more ether linkages in $\mathbf{P - 2 0 6 0 2 0}$ and $\mathbf{P}$ $\mathbf{4 0 4 0 2 0}$ which were easy to decomposition, the initial weight loss temperature was low. The temperatures
Table II. Thermal properties of the copolyamides

\begin{tabular}{cccccc}
\hline Copolymer & $\begin{array}{c}T_{\mathrm{g}} \\
\left({ }^{\circ} \mathrm{C}\right)^{\mathrm{a}}\end{array}$ & $\begin{array}{c}T_{5 \%} \\
\left({ }^{\circ} \mathrm{C}\right)^{\mathrm{b}}\end{array}$ & $\begin{array}{c}T_{10 \%} \\
\left({ }^{\circ} \mathrm{C}\right)^{\mathrm{c}}\end{array}$ & $\begin{array}{c}T_{\max } \\
\left({ }^{\circ} \mathrm{C}\right)^{\mathrm{d}}\end{array}$ & $\begin{array}{c}C_{\mathrm{y}} \\
(\%)^{\mathrm{f}}\end{array}$ \\
\hline $\mathbf{P - 1 0 1 0 8 0}$ & $-\mathrm{g}$ & 504 & 538 & 582 & 55 \\
$\mathbf{P - 1 0 2 0 7 0}$ & - & 518 & 536 & 578 & 56 \\
$\mathbf{P - 1 0 3 0 6 0}$ & 351 & 504 & 521 & 552 & 56 \\
$\mathbf{P - 2 0 2 0 6 0}$ & 340 & 496 & 514 & $557,562^{\mathrm{e}}$ & 53 \\
$\mathbf{P - 2 0 3 0 5 0}$ & 324 & 511 & 526 & 571 & 54 \\
$\mathbf{P - 2 0 6 0 2 0}$ & 314 & 486 & 509 & 518 & 62 \\
$\mathbf{P - 3 0 1 0 6 0}$ & 328 & 499 & 516 & 563 & 57 \\
$\mathbf{P - 3 0 3 0 4 0}$ & 319 & 506 & 526 & $530,570^{\mathrm{e}}$ & 60 \\
$\mathbf{P - 4 0 2 0 4 0}$ & 303 & 499 & 518 & $529,573^{\mathrm{e}}$ & 55 \\
$\mathbf{P - 4 0 4 0 2 0}$ & 291 & 491 & 509 & 519 & 57 \\
\hline
\end{tabular}

${ }^{\mathrm{a}}$ From DSC measurements conducted at a rate of $20^{\circ} \mathrm{C} / \mathrm{min}$ in nitrogen. ${ }^{\mathrm{b}}$ Temperature for $5 \%$ weight loss in $\mathrm{N}_{2}$, heating rate of $20{ }^{\circ} \mathrm{C} / \mathrm{min}$. ${ }^{\mathrm{c}}$ Temperature for $10 \%$ weight loss in $\mathrm{N}_{2}$, heating rate of $20^{\circ} \mathrm{C} / \mathrm{min}$. ${ }^{\mathrm{d}}$ Temperature for the maximum in $\mathrm{N}_{2}$, heating rate of $20^{\circ} \mathrm{C} / \mathrm{min}$. ${ }^{\mathrm{e}}$ Two peaks in the DTG curves. ${ }^{\mathrm{f}}$ Char yield calculated as the percentage of solid residue after heating from 200 to $800{ }^{\circ} \mathrm{C}$ in $\mathrm{N}_{2} .{ }^{\mathrm{g}}$ not detected.

for $10 \%$ gravimetric loss $\left(T_{10 \%}\right)$, which are important evidence for thermal stability, were in the range of $509-538^{\circ} \mathrm{C}$. The temperatures for $5 \%$ weight loss $\left(T_{5 \%}\right)$ and for the maximum weight loss rate $\left(T_{\max }\right)$ were in the range of $486-518$ and $518-582^{\circ} \mathrm{C}$, respectively. In addition, char yield $\left(C_{\mathrm{y}}\right)$ at $800^{\circ} \mathrm{C}$ for the polymers were about 53-62\% (Table II). These resultant data suggested that the introduction of the aromatic heterocyclic phthalazinone moiety into the polymer backbone retains the excellent thermal stability of Kevlar.

\section{Polymer Crystallinity}

The crystallinity of the copolyamides was examined by wide angle X-ray diffractions obtained on slice samples. All of the polymers exhibited amorphous patterns before being annealed. As shown in Figure 4, the representative polyamides exhibited broad dispersive peaks of diffraction at around $2 \theta=20-22^{\circ}$. This observation is quite reasonable because the presence of twist non-coplanar conformation of the phthalazinone moiety decrease the intermolecular force be- 

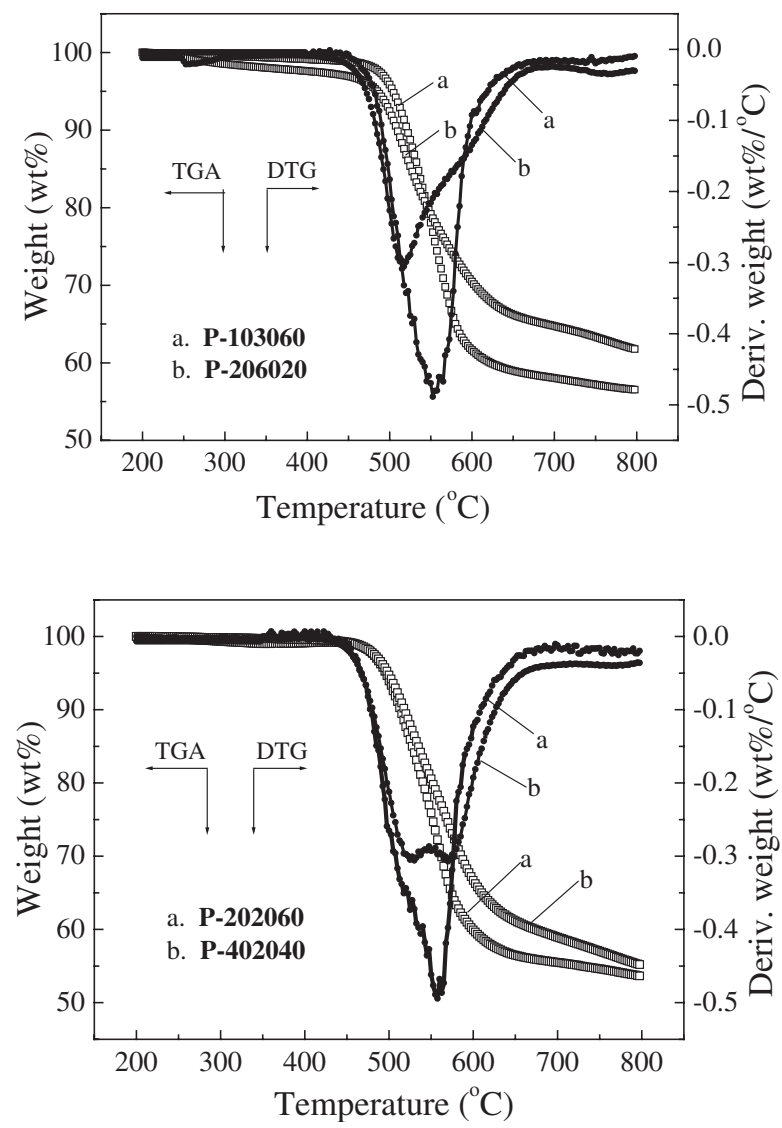

Figure 3. TGA $(\square)$ and DTG (•) curves of copolyamides in nitrogen, heating rate of $20^{\circ} \mathrm{C} / \mathrm{min}$.

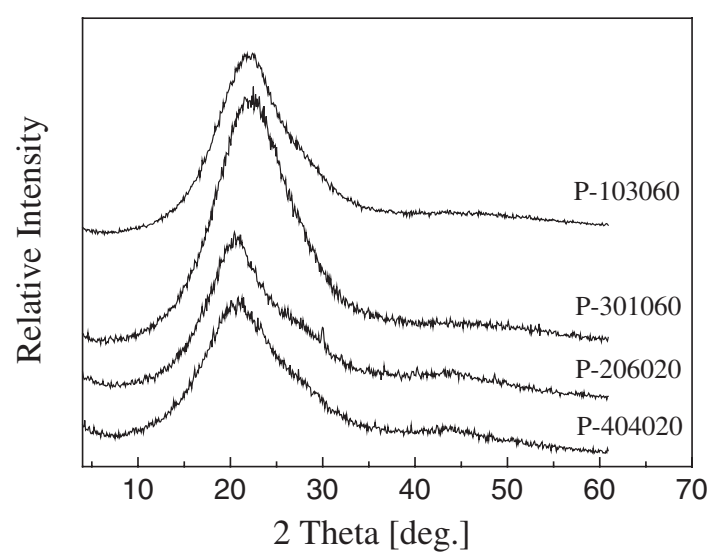

Figure 4. X-Ray diffraction patterns of copolyamides before annealed.

tween the polymer chains, subsequently cause a decrease in crystallinity. However, when the samples were heated up to $360^{\circ} \mathrm{C}$, which is slightly above their $T_{\mathrm{g}} \mathrm{s}$, and kept at this temperature for $2 \mathrm{~h}$, the polymer chains could receive enough energy to overcome the hindrance and rearrange in the more regular form. Then the samples were cooled gradually and the rearranged main chain structures were remained, which imparted the samples with the semicrystalline character. As shown in Figure 5, several obvious diffraction

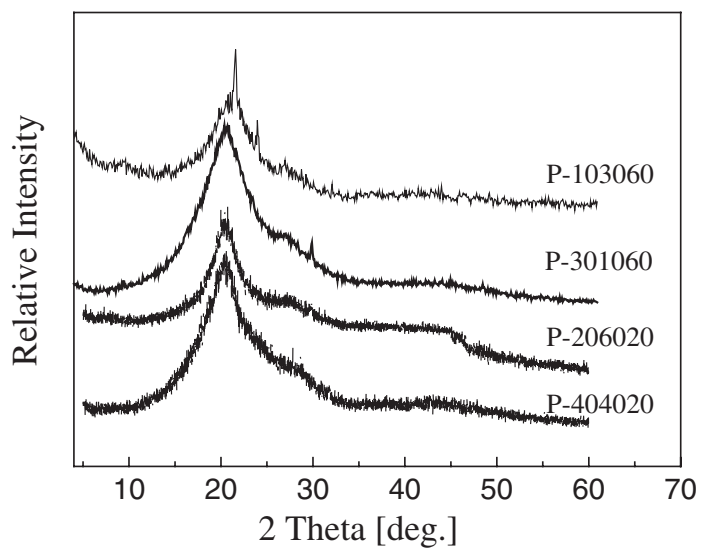

Figure 5. X-Ray diffraction patterns of copolyamides after annealed.

peaks in their X-ray diffraction pattern were observed after being annealed. The angle peaks of the spectrum were at $2 \theta=20-23^{\circ}$ corresponding to the intermolecular layer thickness of 4.01-4.38 . Additionally, when the percentages of PPD decreased from 60 to $20 \%$, the thickness increased from $\sim 4.05$ to $\sim 4.35$ $\AA$. These data also indicate that the kink non-planar phthalazinone moiety and ether linkages in the polymer chains increase the disordered state and thus increase the distance of the polymer chains.

\section{Lyotropic Behavior}

For the formation and examination of prospective lyotropic systems, the polymers are dissolved in conc. $\mathrm{H}_{2} \mathrm{SO}_{4}, \mathrm{NMP}(1 \mathrm{wt} \% \mathrm{LiCl}$ ), DMAc (1 wt \% LiCl) or pure NMP, respectively, to form a class of solutions with different concentration in the range of 4-30 wt $\%$. Concentrations higher than $30 \mathrm{wt} \%$ were not investigated since the polymers were not soluble thoroughly in the system. Then the homogeneous polymer solutions were placed on a glass slide and covered with a cover glass and observed on a polarizing light microscope (PLM) under crossed polarizer. The critical concentration $C^{*}$ values in different solvents at room temperature are listed in Table III. Most of these copolyamides formed anisotropic phase in their conc. $\mathrm{H}_{2} \mathrm{SO}_{4}$, NMP (1 wt $\left.\% \mathrm{LiCl}\right)$ and DMAc $(1 \mathrm{wt} \% \mathrm{LiCl})$ solutions, with $C^{*}$ values in the range of 20-28, 5-16 and $4-13 \mathrm{wt} \%$, respectively. The $C^{*}$ of different copolymer in the same solvent varied evidently. With the molar ratio of PPD in the diamines decreased, the density of hydrogen bonds between interchains decreased and the polymer chain became disorder because of the twisted non-coplanar phthalazinone structure and flexible ether linkages. So it needed higher concentration to form LC and thus the $C^{*}$ increased. Table III also shown that the $C^{*}$ values in NMP/LiCl or $\mathrm{DMAc} / \mathrm{LiCl}$ are lower than the corresponding values in conc. $\mathrm{H}_{2} \mathrm{SO}_{4}$. This can be understood as ex- 
Table III. Critical concentration values of the copolyamides

\begin{tabular}{|c|c|c|c|c|}
\hline \multirow[b]{2}{*}{ Copolymer } & \multicolumn{4}{|c|}{$C^{*}(\mathrm{wt} \%)^{\mathrm{a}}$} \\
\hline & Conc. $\mathrm{H}_{2} \mathrm{SO}_{4}$ & $\begin{array}{c}\text { NMP } \\
/ 1 \% \text { wt } \mathrm{LiCl}\end{array}$ & NMP & $\begin{array}{c}\text { DMAc } \\
/ 1 \% \text { wt LiCl }\end{array}$ \\
\hline P-101080 & 22 & $\mathrm{ND}^{\mathrm{b}}$ & ND & - \\
\hline P-102070 & 20 & 6 & ND & - \\
\hline P-103060 & 21 & 5 & ND & 5 \\
\hline P-202060 & 22 & 5 & ND & 4 \\
\hline P-203050 & 23 & 5 & ND & 5 \\
\hline P-206020 & $\ldots^{\mathrm{c}}$ & 13 & 12 & 12 \\
\hline P-301060 & 23 & 6 & ND & 6 \\
\hline P-303040 & 26 & 8 & ND & 6 \\
\hline P-402040 & 28 & 8 & 7 & 6 \\
\hline P-404020 & - & 16 & 14 & 13 \\
\hline
\end{tabular}

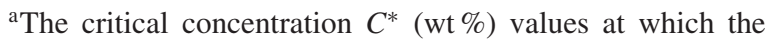
lyotropic phase appears at room temperature. ${ }^{b}$ Not determined for the limited solubility. ${ }^{\mathrm{c}}$ Lyotropic phase was not available under the test condition.

plained by Aharoni that the onset of anisotropy and attainment of full anisotropy are dependent on the magnitude and sign of the polymer-solvent interaction parameter, ${ }^{22}$ the smaller the interaction parameter, the lower the values of the critical concentrations. As representative examples, four photographs of different copolyamides in different solutions at room temperature are shown in Figure 6. Droplet texture, threaded texture, schlieren texture and marbled tex- ture can be separated from these photos, which are the typical texture of nematic liquid crystals.

It is exciting to discover that polyamide containing twist and non-planar moiety and ether linkages in the polymer backbone also exhibit lyotropic liquid crystallinity. The formation of the liquid crystalline solutions of aromatic polyamides is complex and influenced by a combination of factors. ${ }^{15,16}$ In solution the polyamide chains must have an extended rigid chain character including a trans configuration of the amide linkages. The solubility must be sufficiently high to exceed the critical concentration at which the formation of a biphasic solution (liquid crystalline phase coexisting with isotropic phase) occurs. Solubility and chain stiffness are affected by polymer structure, polymer-solvent interactions, aggregation, molecular weight, and temperature. Although the introduction of phthalazinone moiety and ether linkages destroy the tightness of the polymer chains, it improved the solubility and polymer-polar solvent interaction obviously and it is possible to form lyotropic phase in polar organic solvent.

When the solutions were placed under PLM with hot stage, we could observe that the $C^{*}$ values were gradually increased with the temperature. Take P-103060 in $\mathrm{NMP} / \mathrm{LiCl}$ solution for example, the $C^{*}$ value at room temperature $\left(20^{\circ} \mathrm{C}\right)$ was $5 \%$ and when the temperature is $180^{\circ} \mathrm{C}$, the $C^{*}$ value increased to $8.1 \%$.

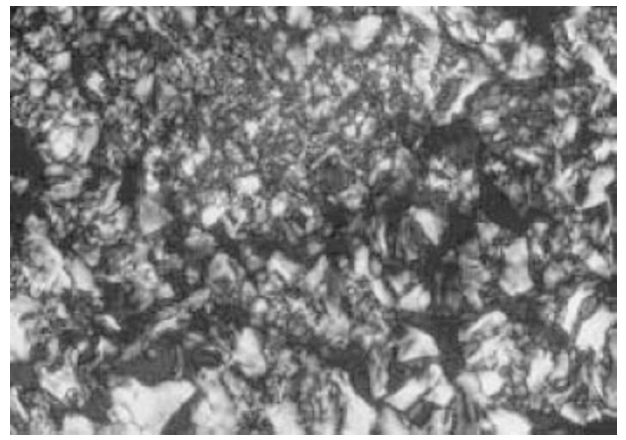

A

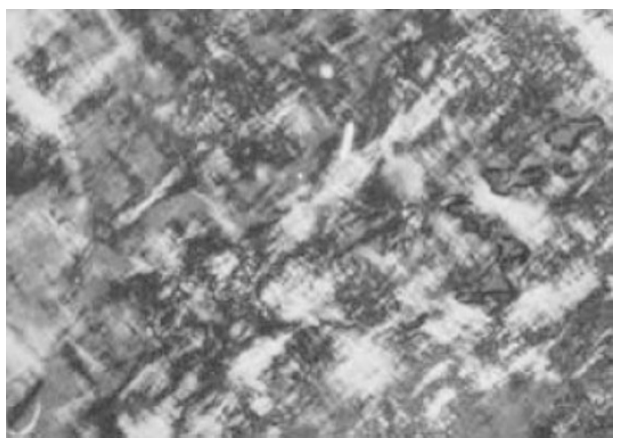

C

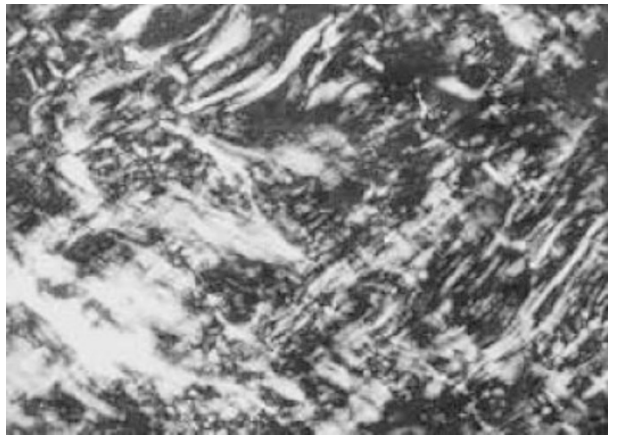

B

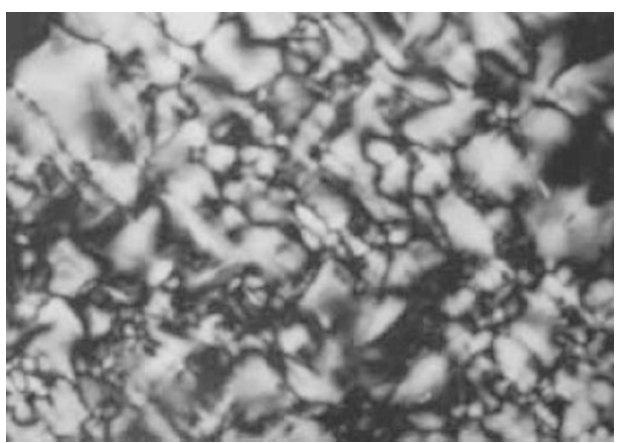

$\mathrm{D}$

Figure 6. Optical micrographs of copolyamide solutions (magnification 40×): (A) P-103060 at 9 wt \% in NMP/LiCl (1\% w/v) solution (droplet texture); (B) P-303040 at $8 \mathrm{wt} \%$ in DMAc/LiCl (1\% w/v) solution (schlieren texture); (C) P-404020 at 16 wt $\%$ in NMP (threaded texture); (D) P-301060 at $25 \mathrm{wt} \%$ in conc. $\mathrm{H}_{2} \mathrm{SO}_{4}$ (marbled texture). 


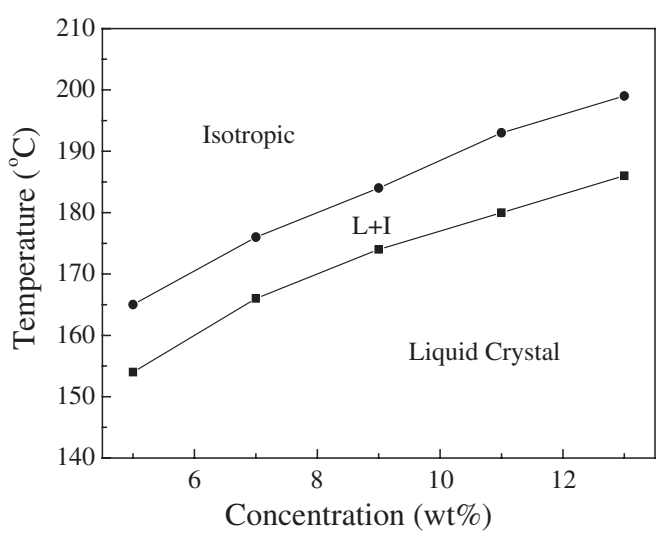

Figure 7. Phase diagram derived from optical microscopy of $\mathbf{P - 1 0 3 0 6 0}$ in NMP/LiCl $(1 \% \mathrm{w} / \mathrm{v})$ solution; The lower curve is the appearance of isotropic inclusions in the LC phase and the upper curve is the disappearance of the birefringence at the nematicisotropic transition temperatures.

The temperature-concentration behavior of the solutions was also observed. When a glass slide with solution was placed on a hot stage between crossed polar, a birefringent (bright) nematic texture was appeared. Upon heating, the LC texture melted and dark areas corresponding to the isotropic phase appeared. Continued heating increased the size of dark areas until they finally coalesced to give a completely isotropic field of view at a temperature $T_{\mathrm{NI}}$, which we defined as the nematic-isotropic transition temperature. The representative phase diagram of $\mathbf{P} \mathbf{- 1 0 3 0 6 0}$ in NMP/ $\mathrm{LiCl}(1 \% \mathrm{w} / \mathrm{v})$ solution is shown as Figure 7 and all the other copolymers had the similar diagram in different solutions.

\section{CONCLUSIONS}

A series of aromatic copolyamides containing phthalazinone moiety and ether linkages were synthesized. The polymers exhibit improved solubility in polar aprotic solvents with or without the addition of $\mathrm{LiCl}$ because the introduction of twisted non-coplanar phthalazinone moiety and flexible linkages. The polymers possessed high $T_{\mathrm{g}}$ values and excellent thermal stability. WAXD measures indicated that the polymers were semicrystalline after being annealed. Observations under PLM demonstrated that the texture of the polymers solutions were nematic lyotropic liquid crystalline in conc. $\mathrm{H}_{2} \mathrm{SO}_{4}, \mathrm{NMP}(1 \mathrm{wt} \% \mathrm{LiCl})$ and DMAc $(1 \mathrm{wt} \% \mathrm{LiCl})$. The polyamides with excellent properties made it possible for the different proc- essing and applications such as dry-wet spinning of fibers or the preparation of films, membranes and coatings.

Acknowledgment. The authors acknowledge with great pleasure the financial support provided by the National High Technology Research and Development Program of China (863, No. 2003AA33G030) and SINOPEC.

\section{REFERENCES}

1. A. A. Collyer, "Liquid Crystalline Polymers: From Structures to Applications," Elsevier Science, London and New York, 1992, chapt. 1-2, p 1.

2. L. S. Park, D. C. Lee, Y. S. Kil, and T. O. Ahn, J. Appl. Polym. Sci., 69, 1517 (1998).

3. T. S. Chung, Polym. Eng. Sci., 26, 901 (1986).

4. K. Rameshbabu and P. Kannan, Liq. Cryst., 31, 843 (2004).

5. R. Cai, J. Preston, and E. T. Samulski, Macromolecules, 25, 563 (1992).

6. S. M. Aharoni, Macromolecules, 12, 94 (1979).

7. J. Preston, "Aramide Fibers. In Kirk-Othmer Encyclopedia of Chemical Technology," 3rd ed., John Wiley \& Sons, New York, 1978, vol. 3.

8. I. K. Spiliopoulos and J. A. Mikroyannidis, Macromolecules, 31, 1236 (1998).

9. M. R. Bellomo, G. D. Pasquale, A. L. Rose, A. Pollicino, and G. Siracusa, Polymer, 37, 2877 (1996).

10. S. H. Hsiao and Y. H. Chang, Eur. Polym. J., 40, 1749 (2004).

11. X. G. Jian and L. Cheng, J. Polym. Sci., Part A: Polym. Chem., 37, 1565 (1999).

12. X. L. Zhu and X. G. Jian, J. Polym. Sci., Part A: Polym. Chem., 42, 2026 (2004).

13. C. Liu, P. T. Liu, J. Y. Wang, C. R. Wu, P. Wang, and X. G. Jian, Chem. J. Chin. Univ., 26, 558 (2005).

14. L. Z. Chen and X. G. Jian, Polym. J., 31, 560 (1999).

15. P. J. Flory, Proc. R. Soc. London, 73, 234 (1956).

16. A. M. Donald and A. H. Windle, "Liquid Crystalline Polymers," H. R. Clauser, Ed., Cambridge University Press, Cambridge, England, 1992.

17. P. J. Flory, "Advances in Polymer Science," Liquid Crystal Polymers I; Springer-Verlag, Berlin, 1984.

18. B. Tamami and H. Yeganeh, Eur. Polym. J., 38, 933 (2002).

19. G. S. Liou and S. H. Hsiao, J. Polym. Sci., Part A: Polym. Chem., 41, 94 (2003).

20. T. H. Su, S. H. Hsiao, and G. S. Liou, J. Polym. Sci., Part A: Polym. Chem., 43, 2085 (2005).

21. D. J. Liaw, F. C. Chang, M. Leung, M. Y. Chou, and K. Muellen, Macromolecules, 38, 4024 (2005).

22. Y. C. Lee and I. J. Chung, Polym. Bull., 28, 441 (1992). 